\title{
Risk of Diabetic Foot in Diabetic Patients with Peripheral Arterial Disease \\ Joshi A
}

Department of Surgery

Bir Hospital,

National Academy of Medical Sciences,

Mahaboudha, Kathmandu, Nepal.

\section{Corresponding Author}

Anip Joshi

Department of Surgery

Bir Hospital,

National Academy of Medical Sciences,

Mahaboudha, Kathmandu, Nepal.

E-mail: anipjoshi@yahoo.com

\section{Citation}

Joshi A. Risk of Diabetic Foot in Diabetic Patients with Peripheral Arterial Disease. Kathmandu Univ Med J. 2020;69(1):38-41.

\section{ABSTRACT}

\section{Background}

The prevalence of peripheral arterial disease is higher in diabetic patients. And $11.6 \%$ of the patients with diabetic foot ulcer have associated peripheral arterial disease.

\section{Objective}

The main objective of the study is to assess the risk of diabetic foot in diabetic patients with peripheral arterial disease.

\section{Method}

This was a case control study conducted in Bir Hospital, National Academy of Medical Sciences (NAMS). The sample size was 173 out of which cases (diabetic foot) and unmatched controls (diabetics without diabetic foot) were divided in the ratio of 1:2. The Odds Ratio (OR) of peripheral arterial disease in diabetic foot was calculated. The study was conducted after taking ethical clearance from Institutional Review Board of National Academy of Medical Sciences.

\section{Result}

There were 173 participants enrolled in the study. Four were excluded, 55 participants were cases of diabetic foot (cases) and 114 participants were diabetics without diabetic foot (controls). The odds of diabetic foot in patients with peripheral arterial disease was $4.12, p<0.001$.

\section{Conclusion}

The risk of diabetic foot in diabetic patients with peripheral arterial disease was higher as compared to diabetic patients without peripheral arterial disease.

\section{KEY WORDS}

Diabetes, Diabetic foot, Peripheral arterial disease 


\section{INTRODUCTION}

Diabetic foot is a complication of diabetes. The risk factors leading to diabetic foot are impaired blood supply, neuropathy and infection. ${ }^{1,2}$ The data from Asia on diabetic foot are sparse. ${ }^{3}$ Among diabetics, $15 \%$ will develop a foot ulcer during their lifetime. ${ }^{4}$ Peripheral Arterial Disease (PAD) is a complication of diabetes. ${ }^{5}$ The early endovascular revascularization and local surgical treatment contributes in limiting amputation levels in patients with diabetic foot infection. ${ }^{6}$ The distal bypass surgery is associated with a high likelihood of limb salvage which shows that the early treatment of PAD in diabetics have a role in reducing the incidence of diabetic foot. ${ }^{7}$ The incidence of PAD in patients with diabetes is four times higher than that in individuals without diabetes. And $11.6 \%$ of the patients with diabetic foot ulcer have associated peripheral vascular disease. ${ }^{8}$

The aim of the study is to determine the risk of diabetic foot in diabetic patients with peripheral arterial disease.

\section{METHODS}

This was a case control study conducted in Bir hospital, National Academy of Medical Sciences (NAMS), from June 2017 to May 2018. The calculated sample size was 173 with consideration of $10 \%$ drop out rate. Out of total sample size, the cases and controls were divided in the ratio of $1: 2$. The controls were unmatched. The inclusion criteria were patient with diagnosis of diabetes, age 1590 years and informed consent and the exclusion criteria were history of lower limb vascular surgery, lower limb amputation, foot gangrene due to diagnosed peripheral arterial disease, myocardial infarction on aspirin therapy and ischemic cerebrovascular disease on aspirin therapy. The operational definition for diabetes was fasting (no caloric intake for $\geq 8$ hours) plasma glucose $\geq 126 \mathrm{mg} / \mathrm{dL}$ (7.0 mmol/L), 2-hour plasma glucose $\geq 200 \mathrm{mg} / \mathrm{dL}$ (11.1 $\mathrm{mmol} / \mathrm{L}), \mathrm{HbA} 1 \mathrm{C} \geq 6.5 \%$ or random plasma glucose $\geq 200$ $\mathrm{mg} / \mathrm{dL}$ (11.1 mmol/L), Ankle Brachial Index (ABI)=Higher of the ankle systolic pressures (posterior tibial or dorsalis pedis)/Higher arm systolic pressure (left or right arm), Normal $-A B I>1$, Claudication - $A B I=0.5-0.7$, Rest pain - $A B I=0.3-0.5$, Gangrene $-A B I<0.3$, peripheral arterial disease was $A B I<0.5 .^{9}$ The data collection was done by interview and questionnaire, physical examination and recorded in a proforma.

The study participants (cases and controls) were recruited from outpatient clinics and wards in Bir Hospital. The participants were explained about the study and informed consent for participation was taken. The participant were interviewed regarding demographic details such as age and sex. The duration of diabetes, use of insulin or anti diabetic drugs, smoking habit and peripheral vascular disease symptoms were noted in the proforma. The study participant were explained about the blood pressure measurement procedure. The participant were asked to lie in supine position. The peripheral pulses status were noted. The brachial systolic blood pressure was taken from brachial artery with sphygmomanometer cuff around the arm by palpatory method and the ankle systolic pressure was taken from dorsalis pedis artery or posterior tibial artery (if dorsalis pedis artery not palpable) with sphygmomanometer cuff around the calf by palpatory method. The data was entered in MS Excel for calculations and statistical analysis was be done by SPSS. The Odds Ratio (OR) of PAD in diabetic foot was calculated. The findings was compared using Chi square test. $P$ value $<0.05$ was taken as statistically significant. The ethical clearance for the study was taken from Institutional Review Board of National Academy of Medical Sciences.

\section{RESULTS}

There were 173 study participants enrolled in the study. Four were excluded as two had ischemic cerebrovascular disease with paraparesis and two had lower limb amputation. Out of 169 study participants, 55 participants were cases of diabetic foot (cases) and 114 participants were diabetics without diabetic foot (controls). The mean age \pm Standard Deviation (SD) of participants in "case" group was $54.5 \pm 12.2$ years and "control" group was $48.8 \pm 16.9$ years. The male:female ratio in DF was $2.6: 1$ and in control group was 0.96:1.

Table 1. Patient characteristics

\begin{tabular}{|lll|}
\hline & Cases & Controls \\
\hline Mean Age $\pm S D$ & $54.5 \pm 12.2$ & $48.8 .8 \pm 16.9$ \\
\hline Male : female & $2.6: 1$ & $0.96: 1$ \\
\hline Mean smoking years \pm SD & $23.96 \pm 8.18$ & $16.10 \pm 6.65$ \\
\hline
\end{tabular}

Table 2. Diabetic foot characteristics

\begin{tabular}{|lll|}
\hline Foot involvement & Location & $\%$ \\
& right & 45.4 \\
& left & 49.0 \\
& both & 5.4 \\
\hline Location of foot ulcer & anterior & 54.6 \\
\hline & middle & 15.6 \\
\hline Meggitt's classification & posterior & 29.6 \\
\hline grade & 0- pre ulcer & $10.9 \%$ \\
\hline & 1-superficial ulcers & $18.1 \%$ \\
\hline 2-deep ulcers & $34.5 \%$ \\
\hline & 3-ulcer c/ bone & $20.0 \%$ \\
\hline involvement & \\
\hline 4-forefoot gangrene & $16.3 \%$ \\
\hline & 5-full foot gangrene & 0 \\
\hline
\end{tabular}


The right and left foot were almost equally affected with both feet involvement in $5.4 \%$ of diabetic foot cases. The location of the foot ulcer was more in the anterior third (54.6\%) than posterior third (29.6\%). The location of foot ulcer was least in the middle third (15.6\%). (Table 2) According the Meggitt's classification, the most common was grade $2(34.5 \%)$ followed by grade $3(20 \%)$.

Table 3. Peripheral arterial disease versus Diabetic foot

\begin{tabular}{|c|c|c|c|c|}
\hline & \multicolumn{4}{|c|}{ Diabetic foot } \\
\hline \multirow{4}{*}{$\begin{array}{l}\text { Peripheral arterial } \\
\text { disease }\end{array}$} & & Yes & No & \\
\hline & Yes & 24(a) & $18(b)$ & 42 \\
\hline & No & $31(c)$ & $96(d)$ & 127 \\
\hline & & 55 & 114 & 169 \\
\hline
\end{tabular}

(Odds Ration $=\mathrm{ad} / \mathrm{bc}$ )

The odds of diabetic foot in patients with peripheral arterial disease (as determined by $\mathrm{ABPI}<=0.9$ ) was 4.12 , $\mathrm{P}<0.001$.

\section{DISCUSSION}

Diabetic foot presents as a major concern for patients with diabetes and for those who treat them, from both a quality of life and an economic standpoint. The diabetic foot ulcers take a longer duration for healing because of multifactorial causes such as metabolic, neuropathy, edema and peripheral arterial disease. ${ }^{10}$ Premalatha et al. concluded that $A B I$ is a good screening tool for diagnosis of peripheral arterial disease but patients with significant stenosis would be missed. ${ }^{11}$

In our study, the odds ratio of diabetic foot in diabetic patients with peripheral arterial disease was 4.12, $p<0.001$. Tressiera et al. have shown that there is an association between peripheral arterial disease and diabetic foot (OR $3,95 \% \mathrm{Cl} 1.087-8.242, \mathrm{p}<0.001) .{ }^{12}$ The finding is similar to the finding from our study. The incidence of peripheral arterial disease in patients with diabetes is at least four times higher than that in individuals without diabetes and it increases with the patient's age and duration of diabetes.12 PAD prevalence is significantly higher in diabetic patients as compared to normal subjects and the atherosclerotic changes is more severe in distal segments of lower extremity. ${ }^{13}$ An outpatient clinic study from an academic institute in Eastern Nepal showed that 1\% of the patients with diabetes had diabetic foot and none had peripheral vascular disease as complications. ${ }^{14}$ This finding can be justified as the study was conducted in outpatient clinic only and it was of shorter duration. In Critical Limb Ischemia diabetic patients with ischemic foot ulcer, the vascular involvement is extremely diffuse and particularly severe in tibial arteries, with high prevalence of long occlusions. ${ }^{15}$ The lower limb atherosclerosis in diabetes is more severe in distal segments of the lower extremity while the proximal segments remain less attenuated compared with patients without diabetes. ${ }^{5}$ Many diabetic patients will need revascularisation to achieve timely and durable healing of diabetic foot ulcers. ${ }^{16}$ This shows that in cases of diabetic foot, patients need to be investigated for associated PAD and subsequently treated. The management modality of diabetic foot ranges from treatment of chronic diabetic foot ulcer to amputation. Van et al. showed that in comparison to patients without diabetes, patients with diabetes were more than seven times as likely to have a lower extremity amputation and emphasizes that aggressive collaboration of vascular surgery and podiatry can be effective in preventing lowerextremity amputation. ${ }^{17}$ This also highlights the need for timely treatment of peripheral vascular disease in patients with diabetic foot to prevent amputation.

In our study, the classification of diabetic foot showed that the most common was grade 2 (34.5\%) followed by grade $3(20 \%)$ according to Meggitt's classification. This was similar to the study by Sharma et al. where the most common diabetic foot was grade $2(53.4 \%)$ followed by grade $3(20.9 \%) .{ }^{8}$ As the most common diabetic foot is grade 2 and grade 3 , an aggressive and multimodality treatment can prevent lower limb amputations. Pomposelli et al. have shown the justification regarding the routine use of pedal arterial reconstruction for patients with diabetes with ischemic foot complications. ${ }^{7}$

In patients with diabetic foot, the patients with and without peripheral arterial disease differ in clinical characteristics, outcome and predictors of outcome. ${ }^{15}$ Prompers et al. concluded that the predictors of healing differs between patients with and without peripheral arterial disease, suggesting that diabetic foot ulcers with or without concomitant peripheral arterial disease should be defined as two separate disease states. ${ }^{18}$

The temporal relationship of diabetic foot in diabetic patients with and without peripheral arterial disease is not compared in this study.

\section{CONCLUSION}

The risk of diabetic foot in diabetic patients with peripheral arterial disease was higher as compared to diabetic patients without peripheral arterial disease. 


\section{REFERENCES}

1. Ulbrecht JS, Cavanagh PR, Caputo GM. Foot problems in diabetes: an overview. Clin Infect Dis. 2004;39:73-82. https://doi. org/10.1086/383266

2. Boyko EJ, Ahroni JH, Stensel V, Forsberg RC, Davignon DR, Smith DG. A prospective study of risk factors for diabetic foot ulcer: the Seattle Diabetic Foot Study. Diabetes Care. 1999; 22: 1036-42. PMID:10388963

3. Boulton AJM, Vileikyte L, Ragnarson-Tennvall G, Apelqvist J. The global burden of diabetic foot disease. Lancet. 2005; 366: 1719-24. PMID:16291066DOI:10.1016/S0140-6736(05)67698-2

4. Reiber GE, Boyko E, Smith DG. Lower extremity ulcers and amputations in individuals with diabetes. In: Harris MI (ed) Diabetes inAmerica, $2^{\text {nd }}$ ed. Bethesda, MD: National Institutes of Health 1995: 409-27.

5. Tapp RJ, Balaku B, Shaw JE, Valensi P, Cailleau M, Eschwege E. Association of glucose metabolism, smoking and cardiovascular risk factors with incident peripheral arterial disease: the DESIR study. Atherosclerosis. 2007;190(1):84-9. PMID: 16674960DOI:10.1016/ j.atherosclerosis. 2006.02.017

6. Troisi N, Ercolini L, Chisci E, Baggiore C, Chechi T, Manetti F et al. Diabetic Foot Infection: Preliminary Results of a Fast-Track Program with Early Endovascular Revascularization and Local Surgical Treatment. Ann Vasc Surg. 2016;30:286-91. https://doi. org/10.1016/j.avsg. 2015.07.015

7. Pomposelli FB, Kansal N, Hamdan AD, Belfield A, Sheahan M, Campbell $D R$, et al. A decade of experience with dorsalis pedis artery bypass: analysis and outcome in more than 1000 patients. J Vasc Surg. 2003; 37: 307-15. DOI: https://doi.org/10.1067/mva. 2003. 125.

8. Sharma VK, Khadka PB, Joshi A, Sharma R. Common pathogens isolated in diabetic foot infection in Bir Hospital. Kathmandu University Medical Journal. 2006;4(3): 295-301. PMID:18603922

9. American Diabetes Association (ADA) Diabetes Guidelines 2016. National Diabetes Education Initiative. www.ndei.org
10. Reiber GE, Lipsky BA, Gibbons GW. The Burden of Diabetic Foot Ulcers. Am J Sur. 1998;176:5-10. https://doi.org/10.1016/S00029610(98)00181-0

11. Premalatha G, Ravikumar R, Sanjay R, Deepa R, Mohan V. Comparison of Colour Duplex Ultrasound and Ankle-Brachial Pressure Index Measurements in Peripheral Vascular Disease in Type 2 Diabetic Patients with Foot Infections. JAPI. 2002;50:1240-4. http://www.japi. org

12. Tressiera-Ayala MA, Garcia Rojas A. Association between peripheral arterial disease and diabetic foot ulcers in patients with diabetes mellitus type 2. Med Univer. 2017; 19: 123-6.

13. Feen C, Neijens FS, Kanters SD, Mali M, Stolk RP, Banga JD. Angiographic distribution of lower extremity atherosclerosis in patients with and without diabetes. Diabet Med. 2002;19: 366-70.

14. Maskey R, Shakya DR, Sharma SK, Karki P, Lavaju P. Diabetes mellitus related complications in outpatient clinic of tertiary care hospital. J Coll Med Sci. 2011;7:9-16.

15. Graziani L, Silvestro A, Bertone V, Manara E, Andreini R, Sigala A, et al. Vascular Involvement in Diabetic Subjects with Ischemic Foot Ulcer: A New Morphologic Categorization of Disease Severity. Eur J Vasc Endovasc Surg. 2007; 33: 453-60. https://doi.org/10.1016/j.ejvs. 2006.11.022

16. Cavanagh PR, Lipsky BA, Bradbury AW, Botek G. Treatment for diabetic foot ulcers. Lancet. 2005; 366: 1725-35. https://doi.org/10.1016/ s0140-6736(05)67699-4

17. Van Gils CC, Brinton EA, Wheeler LA, Mason S, Mellstrom M, Wheeler CG. Amputation Prevention by Vascular Surgery and Podiatry Collaboration in High-Risk Diabetic and Nondiabetic Patients. Diabetes Care. 1999;22:678-83. http://doi.org/10.2337/diacare.22.5.678

18. Prompers L, Schaper N, Apelqvist J, Edmonds M, Jude E, Mauricio D, et al. Prediction of outcome in individuals with diabetic footulcers: focus on the differences between individuals with and without peripheral arterial disease. The EURODIALE Study. Diabetologia. 2008; 51: 74755. https://doi.org/10.1007/s00125-008-0940-0 